\title{
THE FIXATION OF MAMMALIAN CHROMOSOMES
}

\author{
ROBERT T. HANCE \\ Zoological Laboralory, University of Pennsylvania \\ TWO TEXT FIGURES AND THREE PLATES
}

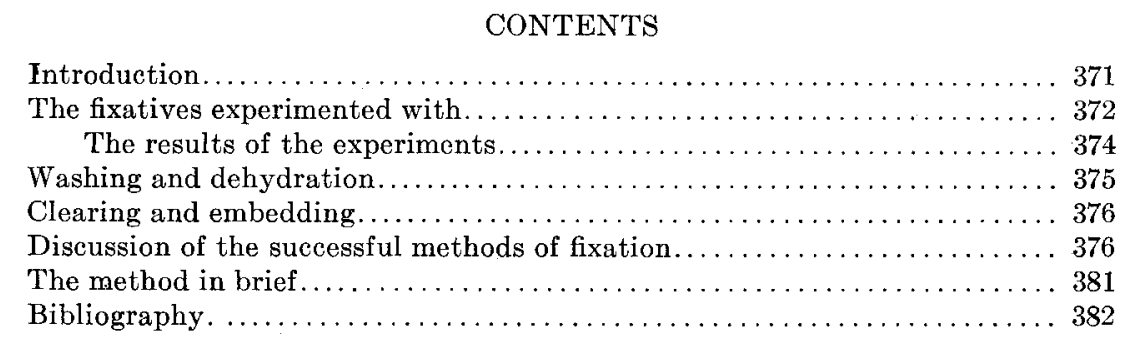

\section{INTRODUCTION}

The advance of mammalian cytology has been exceedingly slow, due partly to the difficulty of obtaining material showing the proper stages of mitosis in sufficient numbers but largely to the fact that the various methods of technique in use were not at all successful in preserving the structures of these small cells. The first difficulty is obviated by securing material from a large number of animals and examining a small portion of tissue from each animal (not more than one or two slides). Eventually a tissue may be found that is in, what might be called, a 'cycle of division,' when the mitotic figures are present in large numbers and a choice of good stages is readily made. This is true for germ as well as somatic tissue. The question of the preparation of mammalian tissue for cytological work forms the body of this paper.

During the early part of this work I had the benefit of the experience of Dr. Ezra Allen in his studies on the fixation of rat tissues (1) and Dr. McClung has assisted me all through my 
experiments with suggestions and criticisms. To these men I am exceedingly grateful.

Several years ago I began a study of the chromosomes of the pig but this had to be abandoned because of the hopelessness of analyzing the chromosome complexes. Even as my figures were then, they were as good as most of the published figures of mammalian mitosis. Since unlimited material was needed for experiments on technique and since there was a fairly large supply of cats available, the early work was carried out on cat testes and the method most successful on this tissue was tried on various other mammals. For some reason I have been unable to obtain the beautiful cytological preparations that Dr. Allen gets by the use of his picro-formol-acetic-chromic mixture, although I get excellent general fixation with it. This may possibly be due to the fact that his fixing fluid was developed with special reference to the rat. With the following method, however, I get very constant results which are, I believe, comparable in every respect to those obtained by Dr. Allen. Furthermore the fixation is not only constant for one mammal but has worked with uniformly good results on seven mammals and on the somatic as well as the germ cells. With two available methods in the field the difficulties besetting mammalian cytology should be much reduced.

\section{THE FIXATIVES EXPERIMENTED WITH}

In the experiments on technique that have been carried on in the Zoological Laboratory of the University of Pennsylvania for a number of years it has been found of value to vary the temperature at which fixing fluids are used. All the fluids tried by me were used as indicated at blood heat and. at about 4 or $5^{\circ} \mathrm{C}$. As I had previously failed to obtain good results at room temperature I did not, except in a few instances, experiment further at this degree.

An attempt was also made to study the effect of varying the time between the removal of the tissue from the body and the placing of it in the fixing medium. In the following table the 
fluids used are outlined and also the methods of applying each fixative. In many cases the experiment was repeated when there seemed any chance of obtaining better results with that particular agent.

Table of fixatives

\begin{tabular}{|c|c|c|c|}
\hline FLUID & TEMPERATURE & TIME IN FLUID & $\begin{array}{l}\text { TIME THAT ELAPSED } \\
\text { BEFORE FIXATION }\end{array}$ \\
\hline & deg. $C$. & hours & \\
\hline Bouin........... & 38 and 4 & 24 & Immediate \\
\hline B.2 + urea $(1)$ & 38 and 4 & $\begin{array}{l}21,23,24 \text { and } \\
\quad 49\end{array}$ & $\begin{array}{l}\text { Immediate and in } 15 \\
\text { minutes }\end{array}$ \\
\hline B.3 (2). & 38 & 24 & Immediate \\
\hline B. $3+$ urea...... & 38 and 4 & 24 & Immediate \\
\hline Carnoy...$\ldots \ldots \ldots$ & 4 & 24 and 49 & Immediate \\
\hline Ohlmacher... & 4 & 24 and 48 & $\begin{array}{l}\text { Immediate and in } 15 \\
\text { minutes }\end{array}$ \\
\hline King's solution........ & 4 & $4,6,21$ and 25 & Immediate \\
\hline Allen's solution No. 15 & 38 & 24 & Immediate \\
\hline No $16 \ldots \ldots \ldots \ldots$ & 38 & 24 & Immediate \\
\hline $\begin{array}{c}\text { Flemming strong so- } \\
\text { lution............. }\end{array}$ & $\begin{array}{l}\text { Room, } 38 \text { and } \\
4\end{array}$ & $\begin{array}{l}24,28,30 \text { and } \\
49\end{array}$ & Immediate \\
\hline $\begin{array}{l}\text { Flemming }+ \text { urea } \\
\text { strong solution }\end{array}$ & 38 and 4 & 24 and 49 & $\begin{array}{l}\text { Immediate, } 10,15,20 \text {, } \\
25,30,45,60 \\
\text { minutes and } 41 / 2 \\
\text { hours. }\end{array}$ \\
\hline
\end{tabular}

(1) and (2). B.2 and B.3 are the symbols which are used in this Laboratory to designate two modifications of the picro-formol-acetic preservative. These modificatons are:

Picric acid, aqueous solution......................75 75

Formalin..................................... 15

Glacial acetic acid.............................10 10

To these two solutions are sometimes added 0.5 gram of urea per hundred cubic centimeters.

In controlling the temperature of the fluids I have made use of our constant temperature rooms in the case of material fixed at $38^{\circ} \mathrm{C}$. When the fluids were used cold the vials containing the fixatives were packed in ice in a quart 'Thermos' vacuum jar having a very wide mouth. As this jar is provided with a handle 
it is very convenient to carry about when it is necessary to go some distance for material. Flemming's solution when kept on ice registers about $4^{\circ}$ to $5^{\circ} \mathrm{C}$. Ice can be kept in this jar for several days.

\section{The results of the experiments}

The judgment that is passed on material prepared for cytological work must be based on two points:

1. The general fixation. If this is not good (i.e., if shrinkage or general distortion is evident) it paves the way for a very just criticism of any conclusions that may be drawn from the study of the chromosomes in such a tissue. As a rule if the general fixation is poor the chromosomes are not very likely to be decipherable, but should they appear so in shrunken and poorly fixed tissue they might well be regarded as probably abnormal.

2. The clearness of the various stages of the chromosomes and particularly, I think, of the distinctness, differentiation and separation of the chromosomes in the metaphase plate. In mammals, chromosomes that are more or less lumped together, even when it is apparently possible to distinguish the separate elements, do not give a true picture, in either form or number, of the actual conditions. This, I believe, I will be able to demonstrate a little later in this paper. Accepting material in such condition as workable has led several investigators of mammalian chromosomes rather far astray.

With these points in mind the material fixed by the above methods was studied. Most of the fluids used gave good preparations for general histological structure but the chromosomes were clumped and indistinguishable one from another. The first result obtained that approached the fulfillment of the required conditions was when cat testes was placed in cold $\left(4^{\circ}\right.$ to $5^{\circ} \mathrm{C}$.) Flemming's solution to which had been added a little urea. Previous to placing it in the fluid the tissue had been allowed to remain on a glass plate for approximately from ten to twenty minutes. Urea was added, as it had been found in the work of other members of the Laboratory to increase penetration. The 
amount taken has never been accurately determined but a few crystals are added to 5 or $10 \mathrm{cc}$. of fluid bringing the concentration of the urea in the fixative probably to about 0.5 per cent. It is difficult even to surmise why this method of delayed fixation should prove successful. It might be suggested that evaporation or exosmosis might play a part in separating the chromosomes although if this were true we would expect to find considerable shrinkage of the tissue. Slight shrinkage is to be observed in tissue treated in this manner although the chromosomes appear to be in excellent condition as is evidenced by figures $3,5,6, .7,8,9$ and 11 . This procedure gave excellent separation of the chromosomes in the testes and ovaries from a number of cats and with the testes of a few pigs. It was successful with the only cat embryo that was fixed in this way.

It was soon found that mammalian tissue could be fixed with better results, as far as lack of shrinkage was concerned, than those obtained by the above method if the material was cut into very small pieces (not more than 2 or $3 \mathrm{~mm}$. in diameter) and placed immediately into cold Flemming plus urea. It is well not only to cut small pieces but to actually tease the tissue finely in the cold Flemming solution so as to obtain rapid penetration. When pieces too large are placed in the fixing solution good results are only obtained in a narrow area around the outside of the piece. The tissue may or may not blacken when placed in the cold Flemming. The absence of the usual blackness is not necessarily indicative of poor fixation.

\section{WASHING AND DEHYDRATION}

All Flemming fixed material was washed for about twentyfour hours in running water or, when this was impractical, many changes of water were made. Dr. Allen's automatic dehydrating device (1) is a great saver of time as it does away with the necessity of handling the material so many times. In the Laboratory I use it constantly but it is impossible to make use of it in field work. I have obtained as good results by dehydrating in the usual way making the steps in the ascending series of alcohols very gradual. 


\section{CLEARING AND EMBEDDING}

When the material is in 95 per cent alcohol cedar oil is added and is usually allowed to remain on the tissue at least twelve hours, one or two changes being made during this time. The cedar oil is displaced with xylol and the material is embedded in paraffin in the usual way (2).

\section{DISCUSSION OF THE SUCCESSFUL METHODS OF FIXATION}

The latter method (i.e., involving the immediate placing of the tissue in the fluid) is not, as is the first, open to the possible criticism that the length of time between the removal of the tissue from the body and the placing of it in the fixing medium might allow pathological changes to enter. At present I am not of the opinion that the short wait between the removal and killing does produce anything abnormal other than a slight shrinkage. The chromosomes appear sharp and well separated and exhibit considerable differentiation. Some difference in the general morphology of the chromosomes is apparent in figures 10 and 11 . Figure 10 is from the testes of a guinea-pig that was fixed immediately while figure 11 is from a testis of another individual fixed by the 'delayed' method ten minutes). 'The chromosomes in the 'delayed' fixation (fig. 11) are thinner and less differentiated than those of figure 10 although they are better separated. Whether this is a result of the method of preparation or not I cannot say at present. It will take considerable study and comparison to determine exactly whether this technique produces any abnormalities in the chromosomes and this study I have not completed as yet. However, since the plan of immediate fixation in cold Flemming plus urea has proved universally successful with mammalian tissue in my work, and as it is not open to the criticism pointed out above, I should suggest that it be followed in preference to the other method, using the delayed fixation only in case of the possible failure of immediate fixation.

Another point of great importance no matter which method is followed--is that the material used must be absolutely fresh. This cannot be emphasized too strongly and is another condition 
that may help to account for some of the inaccuracies in the published results of mammalian chromosome studies. Early in my work on cat testes I found that testes removed from cats that had been dead not more than a half hour and whose bodies were still warm were hopeless for a chromosome study. Recently I have confirmed this observation on the testes of ten pigs which were received after having been removed from the animals for from ten to thirty minutes. The general fixation was excellent but the chromosomes were clumped together ${ }^{1}$ and there was no recognizable differentiation in the size and shape of the chromosomes such as is discernible in tissue which has been killed when absolutely fresh. In text-figure 1 are shown the round shapeless masses of chromatin that result from improper fixation or from the fixation of stale tissue. Such figures do not give a true picture of the actual structure of the chromosomes and it seems very likely that frequently several chromosomes may be fused thus giving an erroneous impression of the total number. I recently prepared the testes, as they were removed, from eight pigs and the fixation (immediate immersion in cold Flemming) was excellent in each case. Figure 13 was drawn from a cell in this lot of material. Text figure 2 is a photograph of a brain cell in a well fixed pig embryo. Judging from the number of chromosomes that have been reported for the pig (eighteen) (3), my own early results (about twenty-four) on this animal in comparison with my present results (over forty) it would seem exceedingly probable that a fusion had taken place between many of the chromosomes in the studies showing lower numbers. This cannot be accounted for by assuming that a difference in the breed of pig might cause the great variation as I have, among others, material from the same breed as reported on by Wodsedalek (Poland China). Figure 3 represents a spermatogonial division in a Poland China boar. It might be suggested at this

\footnotetext{
${ }^{1}$ The tendency for closely associated chromosomes to fuse and appear as one when poorly fixed has been strikingly illustrated in the studies of Dr. P. W. Whiting and myself on the chromosomes of the mosquito. In these studies the actual conditions, particularly in the somatic cells, were long obscured by the tendency for closely approximated chromosomes to run together. This condition has been discussed in our papers ( 4 and 3 ).
} 
point that staleness of tissue as well as improper technique may account for the great variation in the number of chromosomes reported for human material as it is very difficult to obtain this tissue in an absolutely fresh condition. It might also be suggested in view of the fact that all the mammals studied by me have over forty chromosomes that when a perfect fixation of human material is attained the number of chromosomes will be
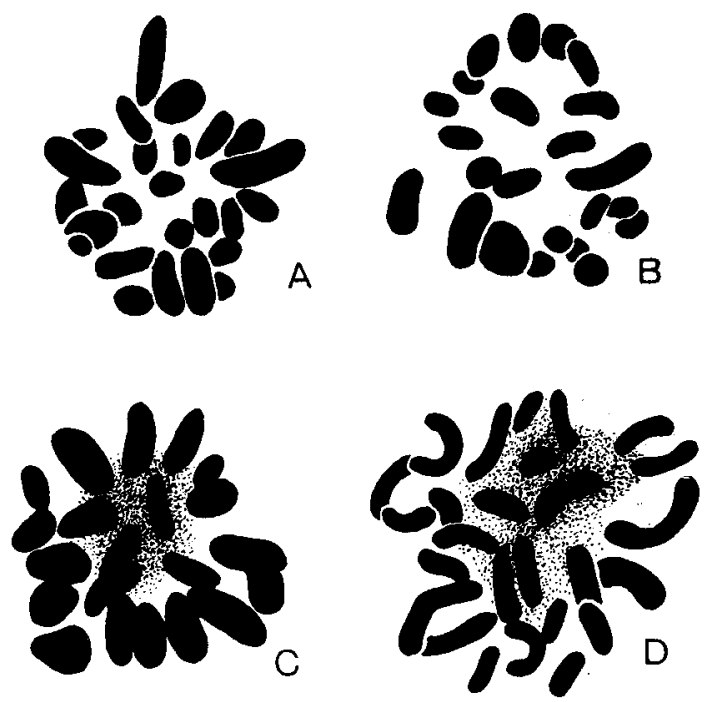

Text fig. $\mathbb{1}$ All four figures represent spermatogonia of the pig in metaphase. $A$ and $B$ illustrate the effect of poor fixation on fresh tissue. The unequal size of the chromosomes would seem to indicate that a fusion between various elements has taken place, and the massing together of these bodies in many cases make it impossible to distinguish the line of separation. Note that the chromosomes tend to be globular in form and lack differentiation.

$C$ and $D$ show the effect of the new method of fixation (immediate immersion in killing fluid) on stale tissue. $C$ was taken from a testicle that had probably been removed from the animal for a longer period of time than had $D$. The large size and small number of the chromosomes of $C$ again suggest that a fusion between chromosomes has taken place. The stipled area is dense and very indistinct. $D$ shows a cell in a slightly better degree of preservation. 'The chromosomes are more numerous and better differentiated than in $C$. The form compares more favorably with the morphology of the chromosomes found in properly preserved material. In $D$ there is also considerable density and lack of distinctness in the center of the chromosome plate indicated in the drawing by the stipled portion. Compare these drawings with figures $1,2,3,4$ and 13 . 
nearer that reported by Winiwarter (forty-eight) than that reported by other investigators.

The fact that a testis that remains in a dead body for a half hour or stands in a gross condition after removal from the body for a similar length of time or even less, shows the chromosomes clumped while tissue that is freshly removed, cut into small pieces and allowed to stand for ten to twenty minutes before

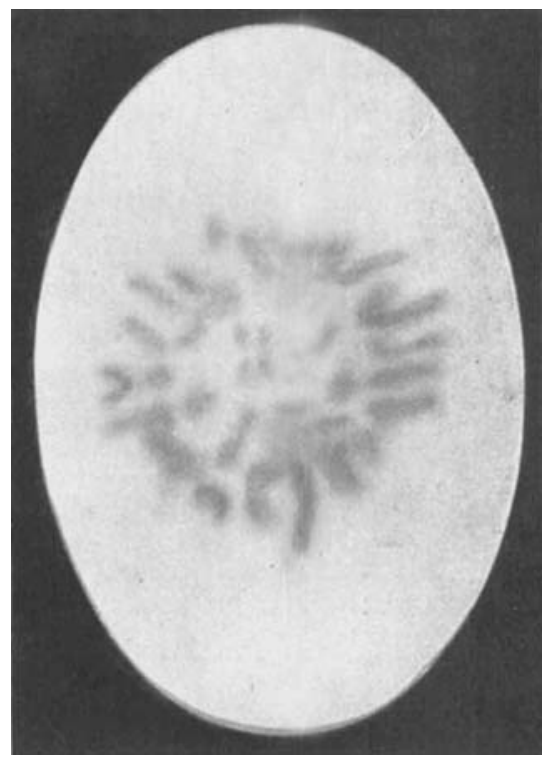

Text fig. 2. This is an enlarged microphotograph of the metaphase chromosomes from the brain of a pig embryo. Figure 2 is a drawing of this cell.

immersion in the killing fluid presents the mitotic figures in apparently excellent condition seems to be contradictory. For the present the fact must stand without explanation as I can offer no suggestion as to the possible reason for this behavior.

It seems probable that the explanation for the success of the cold fixation may lie in the suppression of metabolic activities when the tissue is immersed in the cold medium and the preservation of the living structures until the fluid is able to penetrate and fix them permanently. 
A notable feature of the immediate fixation of mammalian tissue in cold Flemming is the perfect preservation of the extremely delicate splits between chromosomes and of the chromosome forms found in the spermatocyte divisions. These figures have seldom been demonstrated in mammalian studies. Synizesis was not seen in this material except in the center of a piece of tissue which was rather large and where the fixative had not penetrated. Even here it is not the tight ball of threads figured by so many but gives every evidence that it is the result of the extraction of fluid. In my preparations where any evidence of the synizesis of the thin chromatin threads occurs, there is only a slight contraction of the threads away from the nuclear wall appearing as though the fluid which had supported these threads had been removed. The shrinkage usually appears to be equal from all sides although occasionally a cell is found with the chromatin threads massed at one side. In well teased or small pieces of tissue these same stages appear with the threads well separated and there is no shrinkage away from the nuclear wall. That there is something different at this stage is evident but the difference appears to me to be purely a physical one.

I have been much interested in the universality in application of the two methods of fixation of mammalian chromosomes outlined above, I have obtained excellent results with them on the following tissues in the number of cases indicated under the tissue in question. The number in parenthesis under the column

\begin{tabular}{|c|c|c|c|c|}
\hline & TESTES & OVARY & EMBRYO & METHOD OF FIXATION \\
\hline Cat. & 13 & 7 & 1 & $\begin{array}{l}\text { Delayed }(5,6,7) \text { and immediate } \\
\quad(17)\end{array}$ \\
\hline Rat. & 4 & & & $\begin{array}{l}\text { Delayed and immediate (14 and } \\
15)\end{array}$ \\
\hline Guinea-pig. & 2 & & & Delayed (11) and immediate (10) \\
\hline Pig........ & 13 & & Several & $\begin{array}{l}\text { Delayed (3) and immediate (1, 2, } \\
4 \text { and } 13)\end{array}$ \\
\hline Rabbit. & 1 & & & Delayed $(8,9)$ \\
\hline Bat. & & 2 & & Immediate (12) \\
\hline Mouse. . & 4 & & & Immediate (16 and 18 ) \\
\hline
\end{tabular}


headed "Method of Fixation" refer to the figures illustrating the conditions found in the material. As used above 'delayed' indicates that the tissue has been allowed to stand in open after having been removed from the body (for from ten to twenty minutes) while 'immediate' indicates that the tissue had been cut into very fine pieces or teased and plunged immediately into the cold Flemming solution upon removal from the body.

In the case of the pig most of my material has been preserved by the immediate immersion in cold Flemming's solution plus urea. I have a large number of embryos fixed in this manner and as yet have examined only a few. Each one studied has shown uniformly good fixation so far and it may reasonably be expected that the remainder will be equally good since it is fairly evident that the results are not due to a happy accident in one or two isolated cases.

\section{THE METHOD IN BRIEF}

To fix mammalian material for cytological study:

1. Obtain fresh specimens from as many different animals as possible so as to be sure of obtaining one or more in a 'cycle of division.'

2. Place small or finely teased pieces of fresh tissue immediately into cold Flemming's solution plus urea. Allow to remain twenty to twenty-four or more hours.

3 . It is suggested that this second method be not used except in case of the failure of the preceding one. Allow small pieces of fresh tissue to remain in the air for from ten to twenty minutes after removal from the animal before placing them in Flemming's solution plus a little urea which is used at a temperature of about $4^{\circ} \mathrm{C}$. Allow the material to remain in the fluid for twenty to twenty-four or more hours.

4. Wash in water for about twenty-four hours.

5. Dehydrate by very gradual steps.

6. Clear from 95 per cent alcohol in cedar oil followed by xylol.

7. Imbed in paraffin. 


\section{BIBLIOGRAPHY}

(1) Alten, Frra 1916 Studies on the cell division in the albino rat. II. Fx. periments on technique, etc., Anat. Rec., vol. 10, 565-589.

(2) Hance, Robert T. 1916 Notes on embedding in paraffin. Trans. Amer. Mic. Soc., vol. 35, 137-138.

(3) Hance, Robert T. 1917 The somatic chromosomes of the mosquito, Culex pipiens. Jour. Morph., vol. 28, no. 2.

(4) Whiting, Phineas W. 1917 The chromosomes of the common house mosquito, Culex pipiens, L., Jour. Morph., vol. 28, no. 2.

(5) Wodsedalek, J. E. 1913 Spermatogensis of the pig with special reference to the accessory chromosomes. Biol. Bull., vol. 25.

\section{EXPLANATION OF PLATES}

I have used drawings instead of photographs to illustrate the state of preservation in the various cells since drawings show the ehromosomes much more satisfactorily than do photographs in most instances. Furthermore it is difficult to find cells in animals possessing so many chromosomes in which the metaphase plate is flat enough to photograph well although it may be perfectly easy to draw the same plate. I have included one photograph, which, though not good, is probably sufficiently clear to give an idea of the separation of the chromosomes and of their large number (text-fig. 2). Figure 2 is a drawing of the same cell.

All figures were drawn using a Zeiss apochromatic, $1.5 \mathrm{~mm}$. objective and the compensating ocular $12 \times$ which gives an original magnification of $3400 \times$ These drawings were enlarged to twice the original magnification and reduced to approximately $4500 \times$ in reproduction.

\section{PLATE 1}

EXPLANATION OF FIGURES

1 Prophase (late) from the amnion of a pig embryo. Immediate fixation.

2 Polar view of metaphase from the brain of a pig embryo. Immediate fixation.

3 Polar view of metaphase of spermatogonium of pig. Delayed fixation.

4 Polar view of metaphase from the brain of a pig embryo. Immediate fixation.

5 and 6 Polar views of metaphase of spermatogonia of cat. Delayed fixation. 

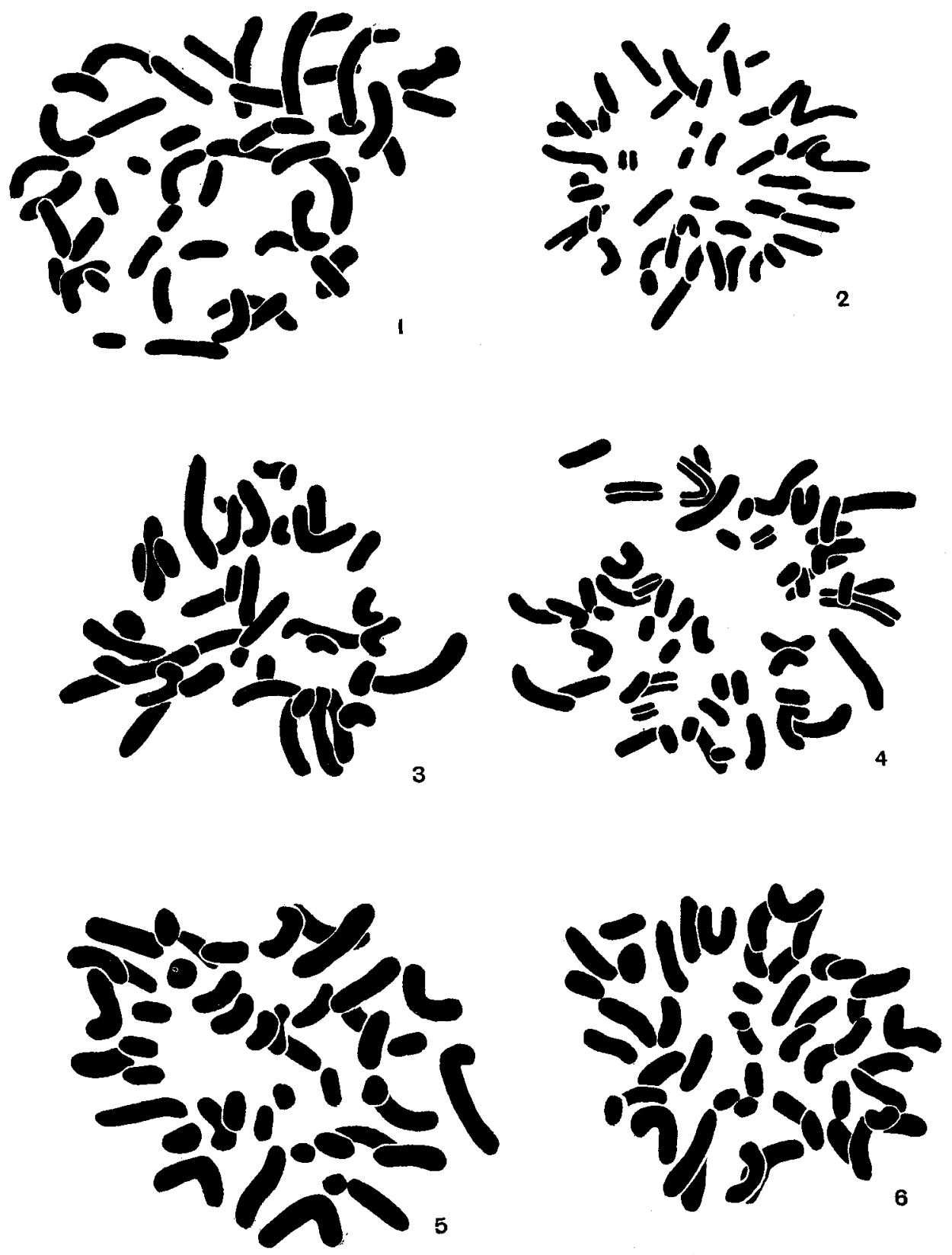


\section{PLA'TE 2}

\section{EXPLANATION OF FIGURES}

$7 \mathrm{a}$ and b Polar view of spermatogonium of a cat found in two sections. Delayed fixation.

8 Side view of the metaphase plate in the spermatogonium of a rabbit. Delayed fixation.

9 Prophase of spermatogonium of rabbit. Delayed fixation.

10 Polar view of metaphase of spermatogonium of a guinca-pig. Immediate fixation.

11 Polar view of metaphase of the spermatogonium of a guinca pig. Delayed fixation. Note the difference in the chromosomes figures 10 and 11.

12 Polar view of metaphase in the ovary of a bat. Immediate fixation. 


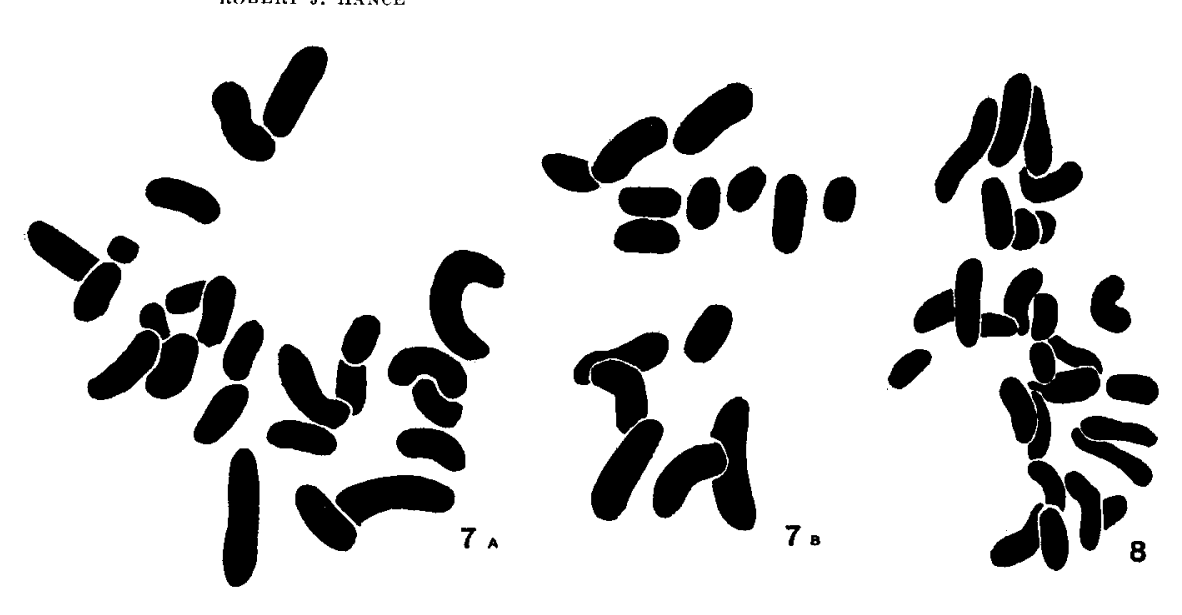

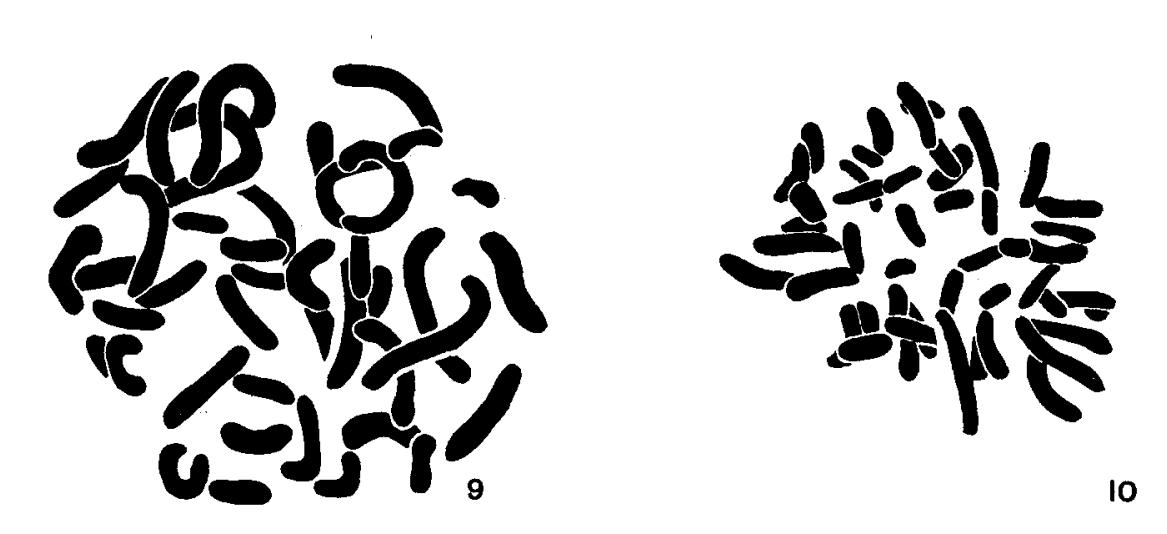

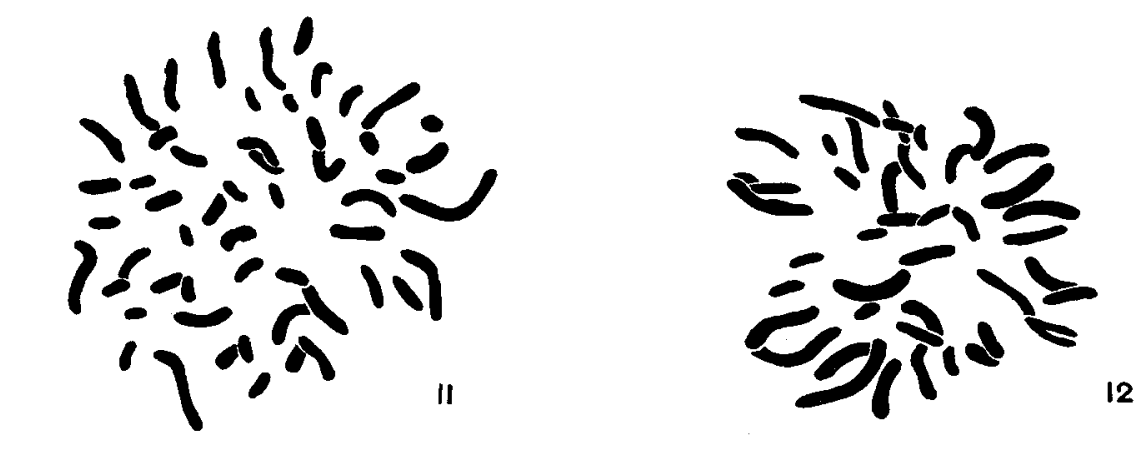




\section{PLATE 3}

EXPLANATION OF FIGURES

13 Polar view of metaphase of spermatogonium of pig. Immediate fixation.

14 Late prophase of spermatogonium of rat. Immediate fixation. This is probably a cut cell.

15 Metaphase of spermatogonium of rat. Immediate fixation. This is a cut cell.

16 Early prophase figures from a first spermatocyte of a mouse. This is only a portion of the cell. Immediate fixation.

17 First spermatocyte figures from the testes of a cat. Note the characteristic forms that have been reported for other forms but seldom for mammals. Immediate fixation. Such forms have been found in all the mammalian tissue studied.

18 A first spermatocyte from the testes of a mouse. An oblique view. Immediate fixation. This is probably a cut cell. 


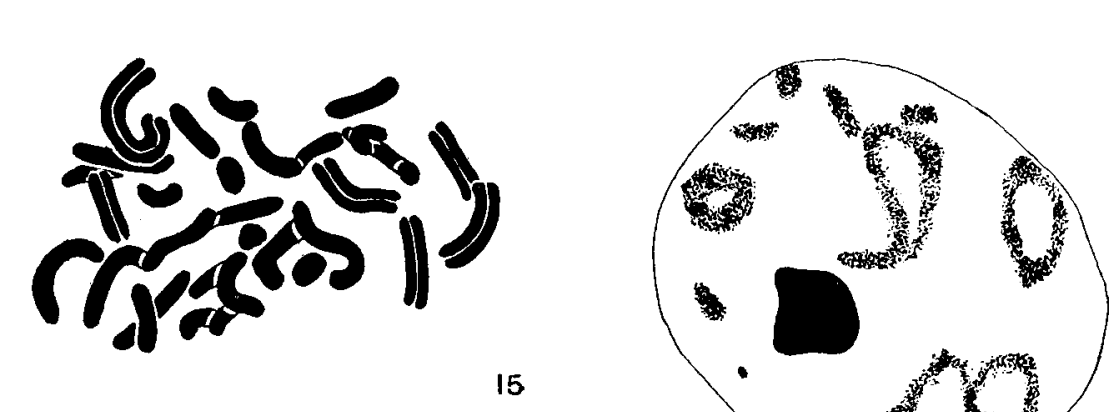

$$
\begin{aligned}
& \text { olik\} }
\end{aligned}
$$

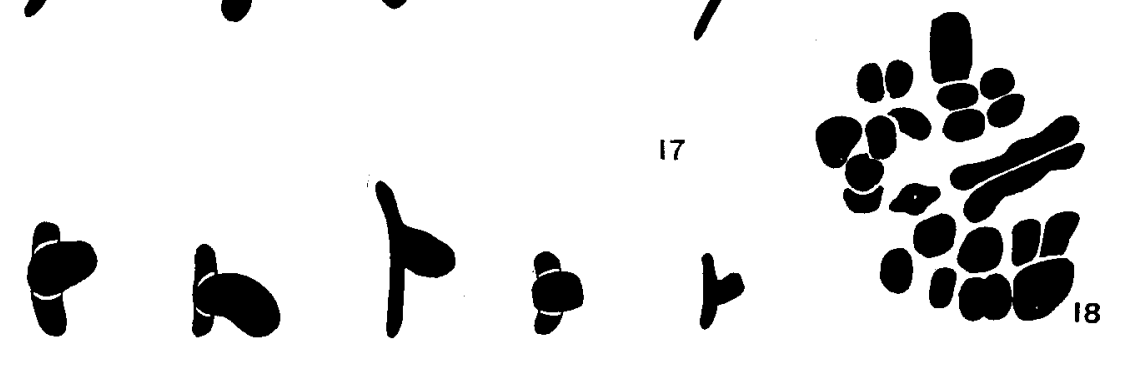

